\title{
Self-Complementary ABC Triblock Copolymers via Ring-Opening Metathesis Polymerization
}

\author{
Hassan S. Bazzi, Jean Bouffard and Hanadi F. Sleiman* \\ Department of Chemistry, McGill University, 801 Sherbrooke Street West, \\ Montreal, QC Canada H3A 2K6
}

Supporting Information 


\section{Experimental Procedures}

General Considerations. All polymerization reactions were carried out under a dry nitrogen atmosphere, using standard Schlenk techniques. ${ }^{1} \mathrm{H}$ NMR spectra were recorded on a Varian M400 spectrometer operated at $400.140 \mathrm{MHz},{ }^{13} \mathrm{C}$ NMR on a Varian M300 spectrometer operated at $75.459 \mathrm{MHz}$. Chemical shifts are reported in ppm relative to the deuterated solvent resonances. UV/VIS spectra were recorded on a Varian Cary 300 spectrophotometer. IR spectra were recorded on a Perkin-Elmer 16PC series FT-IR spectrometer in the range between 4000 and $400 \mathrm{~cm}^{-1}$ with a resolution of $2 \mathrm{~cm}^{-1}$. GPC spectra were recorded using a Waters 510 pump equipped with two polystyrene-packed Styragel columns (HR4 and HR1, 3.9 X $300 \mathrm{~mm}$ ) in series and in-line with a Varian RI-4 detector. THF was used as eluent at a flow rate of $0.6 \mathrm{~mL} / \mathrm{min}$, and the instrument was calibrated with polystyrene standards from Aldrich. DLS experiments were performed on a Brookhaven Instruments Corporation system equipped with a BI-200SM goniometer, a BI-9000AT digital correlator and a Compass 315-150 CW laser light source from Coherent Inc. operating at $532 \mathrm{~nm}(150 \mathrm{~mW})$.

Transmission Electron Microscopy. The diblock copolymer was dissolved in $\mathrm{CH}_{2} \mathrm{Cl}_{2} \quad(1 \% \mathrm{w} / \mathrm{v})$. Samples were prepared by placing a drop of this solution onto Transmission Electron Microscopy (TEM) copper grids (400 mesh, carbon coated, purchased from Electron Microscopy Sciences). The grids were air-dried for 12 hours. The aggregates were then examined using a JEOL 2000FX electron microscope operated at $80 \mathrm{KV}$.

Materials. 6-Bromohexanoyl chloride and other reagents were purchased from Aldrich and used as received. The ruthenium alkylidene catalyst ${ }^{7} \mathbf{1}$ was purchased from 
Strem Chemicals. Monomers $\mathbf{2}^{9}$ and $\mathbf{3}^{10}$ were synthesized according to literature procedures. Tetrahydrofuran (THF) was distilled from sodium/benzophenone, dichloromethane $\left(\mathrm{CH}_{2} \mathrm{Cl}_{2}\right)$ was distilled from $\mathrm{CaH}_{2}$. Deuterated solvents were purchased from Cambridge Isotope Laboratories and used without further purification.

Synthesis of 2-acetylamino-6-[6-bromohexanoylamino]-pyridine 5. In a dry, nitrogen-purged round bottom flask, 2-acetylamino-6-aminopyridine (604mg, 4 mmoles), 6-bromohexanoyl chloride (1.07g, 5 mmoles), triethyl amine (404mg, 4 mmoles), and DMAP (N,N-dimethyl-4-aminopyridine, $30.5 \mathrm{mg}, 0.25$ mmoles) were dissolved in $\mathrm{CH}_{2} \mathrm{Cl}_{2}$ while stirring. White $\mathrm{HCl}$ fumes occurred were initially observed, after which the reaction mixture was refluxed overnight. The solution was cooled down, washed with $5 \%$ aqueous $\mathrm{NaHCO}_{3}$, water, then dried over $\mathrm{MgSO}_{4}$. The organic solvent was removed under vacuum to give a thick light brown liquid. Chromatography (Silica gel, 10\% hexanes in ethyl acetate $)$ yielded a white solid. Yield $=505 \mathrm{mg}(1.54 \mathrm{mmoles}, 38.5 \%) .{ }^{1} \mathrm{H}$ NMR $\delta\left(d_{6}\right.$-DMSO): $10.04(\mathrm{~s}, 1 \mathrm{H}), 9.99(\mathrm{~s}, 1 \mathrm{H}), 7.68(\mathrm{~s}, 3 \mathrm{H}), 3.62(\mathrm{~m}, 1 \mathrm{H}), 3.52(\mathrm{~m}, 1 \mathrm{H})$, $2.39(\mathrm{~m}, 2 \mathrm{H}), 2.08(\mathrm{~s}, 3 \mathrm{H}), 1.85(\mathrm{~m}, 1 \mathrm{H}), 1.70(\mathrm{~m}, 1 \mathrm{H}), 1.58(\mathrm{~m}, 2 \mathrm{H}), 1.39(\mathrm{~m}, 2 \mathrm{H}) .{ }^{13} \mathrm{C}$ NMR $\delta\left(d_{6}\right.$-DMSO): $172.55,169.81,150.93,140.43,109.60,46.06,36.74,32.65,28.01$, 26.75, 24.96. FT-IR (KBr): 3305 (br), 2938, 2863, 1706, 1668, 1587, 1521, 1452, 1369, $1296,1239,1153,1077,1000,957,794,668,587$, and $546 \mathrm{~cm}^{-1}$. UV-Vis: $\lambda_{\max }\left(\mathrm{CHCl}_{3}\right)=$ $254.8 \mathrm{~nm}$ and $330.3 \mathrm{~nm}$. EI-MS: $[\mathrm{M}+\mathrm{Na}]^{+}=350.0$ and 352.0 (Br isotopes). HR-MS: Theoretical calculated for $\mathrm{C}_{13} \mathrm{H}_{18} \mathrm{BrN}_{3} \mathrm{O}_{2}: 327.0582$, found: 327.0587 .

Synthesis of monomer 4. 2-Acetylamino-6-[6-bromohexanoylamino]-pyridine 5 (210mg, 0.64 mmoles), monomer 2 (127mg, 0.77 mmoles), $\mathrm{K}_{2} \mathrm{CO}_{3}$ (531.3mg, 3.25 mmoles) were mixed in dry DMF $(10 \mathrm{~mL})$ in a flame-dried round bottom flask and the 
setup was purged with nitrogen. The mixture was stirred at a constant temperature of $50^{\circ} \mathrm{C}$ for two hours, then cooled down to room temperature. Stirring continued for another hour, then the reaction mixture was poured into $20 \mathrm{~mL}$ of distilled water. The aqueous solution was extracted with ethyl acetate $(60 \mathrm{~mL})$, and the organic fractions were collected, dried over $\mathrm{MgSO}_{4}$. Then, the solvent was evaporated under vacuum to afford yellowish oil. Chromatography (Silica gel, ethyl acetate) yielded a pure white solid. Yield $=144 \mathrm{mg}\left(0.35\right.$ mmoles, 55\%). ${ }^{1} \mathrm{H}$ NMR $\delta\left(d_{6}\right.$-DMSO): $9.98(\mathrm{~s}, 1 \mathrm{H}), 9.91(\mathrm{~s}, 1 \mathrm{H})$, $7.67(\mathrm{~s}, 3 \mathrm{H}), 6.53(\mathrm{~s}, 2 \mathrm{H}), 5.10(\mathrm{~s}, 2 \mathrm{H}), 3.31(\mathrm{~m}, 2 \mathrm{H}), 2.90(\mathrm{~s}, 2 \mathrm{H}), 2.35(\mathrm{~m}, 2 \mathrm{H}), 2.09$ (s, $3 \mathrm{H}), 1.55(\mathrm{~m}, 2 \mathrm{H}), 1.46(\mathrm{~m}, 2 \mathrm{H}), 1.23(\mathrm{~m}, 2 \mathrm{H}) .{ }^{13} \mathrm{C}$ NMR $\delta\left(d_{6}\right.$-DMSO): 177.10, 172.57 , $169.85,150.92,140.48,137.09,109.57,81.05,47.88,38.60,36.68,27.76,26.49,25.29$, 24.84. FT-IR (KBr): 3324 (br), 2942, 2865, 1772, 1696, 1586, 1517, 1449, 1404, 1369, 1296, 1243, 1152, 1030, 879, 853, 803, 720, 651, 594, and $548 \mathrm{~cm}^{-1}$. UV-Vis: $\lambda_{\max }\left(\mathrm{CHCl}_{3}\right)=253.6 \mathrm{~nm}$ and $329.5 \mathrm{~nm}$. EI-MS: $[\mathrm{M}+\mathrm{Na}]^{+}=434.9$. HR-MS: Theoretical calculated for $\mathrm{C}_{17} \mathrm{H}_{20} \mathrm{~N}_{4} \mathrm{O}_{4}$ (monomer 4 lost furan, $\mathrm{C}_{4} \mathrm{H}_{4} \mathrm{O}$, in a retro Diels Alder pathway when it was injected at $200^{\circ} \mathrm{C}$ ): 344.1484 , found: 344.1488 .

Synthesis of polymer 6. Catalyst 1 (10mg, 0.012 mmoles) was dissolved in $1 \mathrm{~mL}$ of $\mathrm{CH}_{2} \mathrm{Cl}_{2}$ and was sonicated for 10 minutes. It was then added dropwise to a dichloromethane solution $(4 \mathrm{~mL})$ of monomer 4 (49.5mg, 0.12 mmoles, 10 equiv.), and the reaction was stirred at room temperature. The color of the solution turned from purple to brown in less than 5 minutes. The solution was stirred for 30 minutes, then ethyl vinyl ether $(0.4 \mathrm{~mL}, 600$ equiv.) was added and stirring continued for 15 minutes. The polymerization solution was then poured into hexanes $(100 \mathrm{~mL})$ while stirring to give a light greenish solid that was collected and dried under vacuum (90\% yield). GPC (THF, 
polystyrene standards): $\mathrm{Mn}=4.2 \times 10^{3}$ and $\mathrm{PDI}=1.11 .{ }^{1} \mathrm{H}$ NMR $\delta\left(d_{6}\right.$-DMSO $)(67 \%$ trans): 9.97 (br, 2H), 7.67 (br, 3H), 5.92 (br, trans), 5.71 (br, cis), 4.85 (br, cis), 4.37 (br, trans), 3.34 (br, 4H), 2.35 (br, 2H), 2.07 (br, 3H), $1.54(\mathrm{br}, 4 \mathrm{H}), 1.23(\mathrm{br}, 2 \mathrm{H}) .{ }^{13} \mathrm{C}$ NMR $\delta\left(d_{6}\right.$-DMSO): $176.10,172.58,169.84,150.94,140.49,132.10,109.60,80.50,53.35$, 38.79, 36.67, 27.73, 26.63, 25.33, 24.84. FT-IR (KBr): 3315 (br), 2934, 2858, 1777, $1701,1586,1508,1449,1400,1369,1295,1242,1150,1038,1007,981,853,802,734$, 642 , and $548 \mathrm{~cm}^{-1}$. UV-Vis: $\lambda_{\max }\left(\mathrm{CHCl}_{3}\right)=254.2 \mathrm{~nm}, 261.0 \mathrm{~nm}$ and $336.0 \mathrm{~nm}$.

The NMR monitoring of the polymerization of monomer 4 was performed in $\mathrm{CD}_{2} \mathrm{Cl}_{2}$ in an NMR tube $([\mathrm{M}] /[\mathrm{I}]=10)$. Monomer Conversion \% was obtained by integration of the olefinic peaks of the polymer and the monomer. The average molecular weight of the resulting polymer was determined by end-group analysis of the olefinic peaks of the polymer versys the $m$-phenyl proton peaks of the end-group $(=\mathrm{CHPh})$. A plot of the molecular weight vs conversion showed a linear relationship indicating that the ROMP reactions of monomer $\mathbf{4}$ is controlled (please see fig. A1).

Figure A.1: Molecular Weight vs Conversion

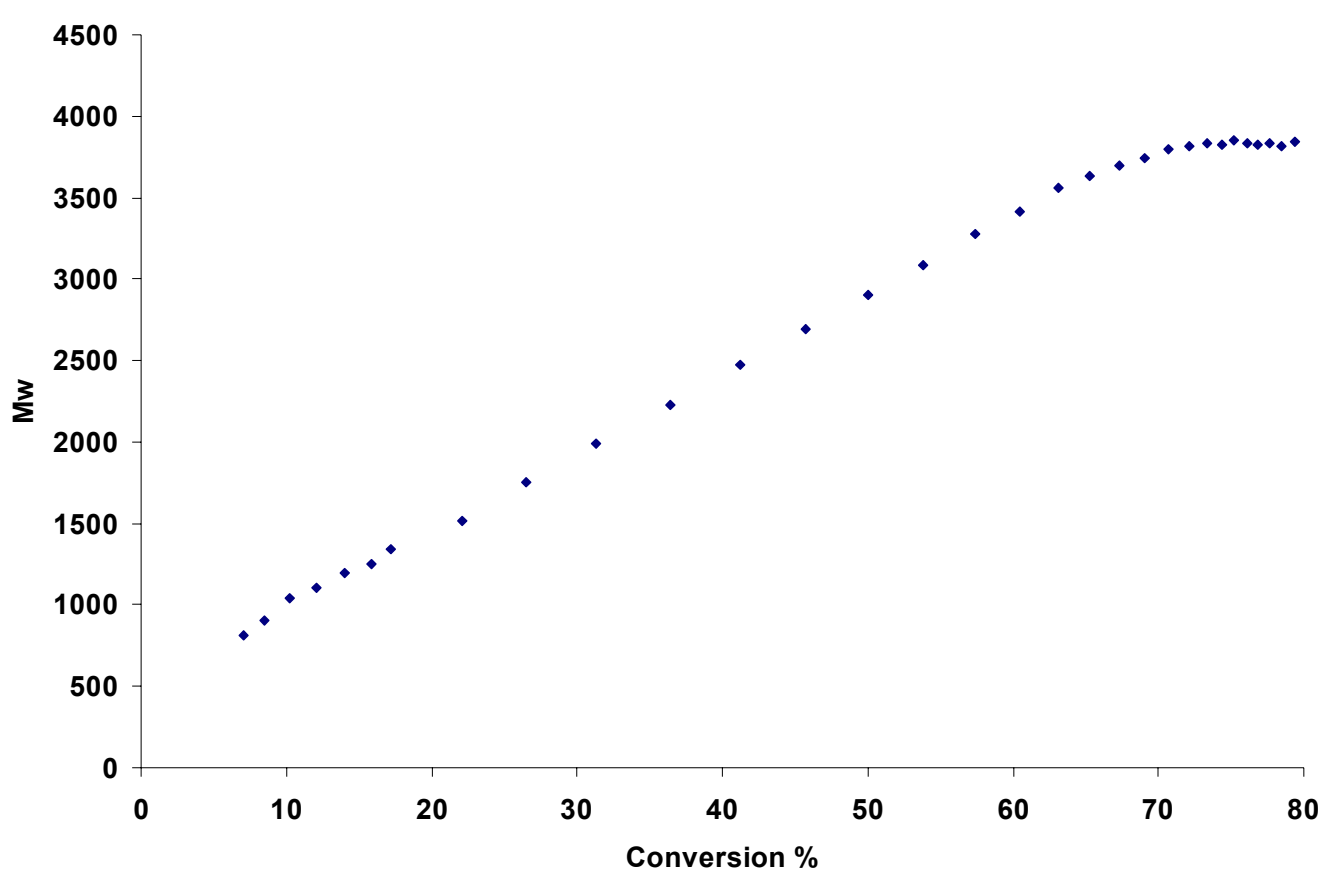


We attribute the observed deviation from linearity after $70 \%$ monomer conversion to the uncertainty in the integration of the polymer end-group peak (which appeared as a broad peak at the later stages of this polymerization).

Synthesis of the ABC triblock copolymer 9. A solution of catalyst 1 (40mg, 0.049 mmoles) in THF (2mL) was sonicated for 10 minutes. It was then transferred to a $3 \mathrm{~mL}$ THF solution of monomer 2 ( $80.3 \mathrm{mg}, 0.49$ mmoles, 10 equiv.) and the resulting solution was stirred at room temperature. The color of the solution changed from purple to brown, indicating full initiation. ${ }^{1} \mathrm{H}$ NMR showed the complete conversion of monomer 2 after 10 minutes, so the solution was split into two halves. The first half was quenched with ethyl vinyl ether $(0.8 \mathrm{~mL}, 600$ equiv.), stirred for 15 minutes and polymer 7 (88\% yield) was collected by precipitating the solution into stirring hexanes, and was dried under vacuum. To the other half, a solution of monomer $3(268.8 \mathrm{mg}, 1.22$ mmoles, 50 equiv.) in THF (2.5 mL) was added and the solution was stirred. NMR showed quantitative conversion after 20 minutes. Again, the solution was split into two equal portions and copolymer 8 ( $82 \%$ yield) was collected the same way as polymer 7 . Finally, a $\mathrm{CH}_{2} \mathrm{Cl}_{2}$ solution ( $\left.3 \mathrm{~mL}\right)$ of monomer $4(50.1 \mathrm{mg}, 0.12$ mmoles, 10 equiv.) was added to the polymerization solution. After stirring for 30 minutes, ${ }^{1} \mathrm{H}$ NMR showed that the monomer was fully consumed. Ethyl vinyl ether $(0.4 \mathrm{~mL})$ was added and the solution was stirred for few minutes then poured into stirring hexanes to afford the triblock copolymer 9 as dark grey solid in $79 \%$ yield.

The other triblock copolymers (12 and $\mathbf{1 4}$ ) were synthesized similarly by changing the order of the addition of the monomers (Same amounts/equivalents were used). 
Polymer 7: GPC (THF, polystyrene standards): $\mathrm{Mn}=2.9 \times 10^{3}$ and $\mathrm{PDI}=1.11 .{ }^{1} \mathrm{H}$ NMR $\delta\left(d_{6}\right.$-DMSO) (80\% trans): 11.20 (s, br, 1H), 5.89 (br, trans), 5.66 (br, cis), 4.86 (br, cis), 4.44 (br, trans), 3.59 (br, 2H). ${ }^{13} \mathrm{C}$ NMR $\delta$ ( $d_{6}$-DMSO): 178.30, 131.78, 80.51, 53.99. FT-IR (KBr); 3207, 3080, 2864, 2767, 1775, 1712, 1344, 1272, 1182, 1037, 972, 892, 755 , and $633 \mathrm{~cm}^{-1}$. UV-Vis: $\lambda_{\max }(\mathrm{THF})=249.0 \mathrm{~nm}$.

Diblock copolymers 8 and 11: GPC (THF, polystyrene standards): $\mathrm{Mn}=17.1 \times 10^{3}$ and $\mathrm{PDI}=1.09\left(\right.$ copolymer 8) and $\mathrm{Mn}=17.6 \times 10^{3}$ and $\mathrm{PDI}=1.12($ copolymer 11$) .{ }^{1} \mathrm{H}$ NMR $\delta$ ( $d_{6}$-DMSO) (84\% trans): $11.22(\mathrm{br}), 5.94$ (br, trans), 5.72 (br, cis), 4.83 (br, cis), 4.41 (br, trans), 3.59 (br), 3.39 (br), $3.32(\mathrm{br}), 1.45(\mathrm{br}), 1.23(\mathrm{br}), 0.86\left(\mathrm{br} .{ }^{13} \mathrm{C}\right.$ NMR $\delta\left(d_{6^{-}}\right.$ DMSO): $178.02,176.50,132.05,131.75,80.60,54.09,53.83,52.69,38.61,29.99,20.28$, 14.37. FT-IR (KBr): 2960, 2874, 1779, 1700, 1439, 1399, 1343, 1190, 1137, 1039, 968, $921,773,764$, and $668 \mathrm{~cm}^{-1}$. UV-Vis: $\lambda_{\max }\left(\mathrm{CHCl}_{3}\right)=250.1 \mathrm{~nm}$.

Triblock copolymers 9, 12 and 14: GPC (THF, polystyrene standards): $\mathrm{Mn}=21.1 \times 10^{3}$ and $\mathrm{PDI}=1.09$ (copolymer 9) and $\mathrm{Mn}=22.7 \times 10^{3}$ and $\mathrm{PDI}=1.14($ copolymer 12$) .{ }^{1} \mathrm{H}$ NMR $\delta$ ( $d_{6}$-DMSO) (84\% trans): $11.21(\mathrm{br}), 9.98(\mathrm{br}), 7.66,5.92$ (br, trans), 5.71 (br, cis), 4.82 (br, cis), 4.41 (br, trans), 3.59 (br), 3.39 (br), 3.32 (br), 2.35 (br), 2.07 (br), 1.50 (br), 1.24 (br), 0.84 (br). ${ }^{13} \mathrm{C}$ NMR $\delta$ ( $d_{6}$-DMSO): 177.97, 176.45, 172.51, 169.79, $150.88,140.46,132.30,132.04,131.75,109.55,80.62,77.19,54.10,53.86,52.71,38.64$, 36.70, 30.03, 27.75, 26.66, 25.37, 24.88, 20.32, 14.41. FT-IR (KBr): 3567 (br), 3320 (br), 2959, 2872, 1776, 1700, 1585, 1507, 1450, 1399, 1344, 1191, 1137, 1038, 968, 921, 803, and $668 \mathrm{~cm}^{-1}$. UV-Vis: $\lambda_{\max }\left(\mathrm{CHCl}_{3}\right)=253.7 \mathrm{~nm}, 260.2 \mathrm{~nm}$, and $336.8 \mathrm{~nm}$.

Polymer 10: GPC (THF, polystyrene standards): $\mathrm{Mn}=15.2 \times 10^{3}$ and $\mathrm{PDI}=1.12 .{ }^{1} \mathrm{H}$ NMR $\delta\left(\mathrm{CDCl}_{3}\right)$ (84\% trans): 6.07 (br, trans), 5.77 (br, cis), 5.02 (br, cis), 4.46 (br, trans), 
$3.47(\mathrm{br}, 2 \mathrm{H}), 3.33(\mathrm{br}, 2 \mathrm{H}), 1.56(\mathrm{br}, 2 \mathrm{H}), 1.32(\mathrm{br}, 2 \mathrm{H}), 0.94(\mathrm{br}, 3 \mathrm{H}) .{ }^{13} \mathrm{C}$ NMR $\delta$ $\left(\mathrm{CDCl}_{3}\right): 175.80,131.98,131.02,81.29,53.74,52.63,39.12,30.08,20.42$, and 14.06. FT-IR $\left(\mathrm{CHCl}_{3}\right): 1773,1699,1398,1370,1340,1192,1137$, and $1043 \mathrm{~cm}^{-1}$. Polymer 13: ${ }^{1} \mathrm{H}$ NMR $\delta\left(d_{6}\right.$-DMSO) (74\% trans): 11.17 (br), 9.91 (br), $7.66(\mathrm{br}), 5.91$ (br, trans), 5.71 (br, cis), 4.86 (br, cis), 4.45 and 4.38 (br, trans), 3.36 (br), 2.35 (br), 2.07 (br), $1.54(\mathrm{br}), 1.25(\mathrm{br}) .{ }^{13} \mathrm{C}$ NMR $\delta$ ( $d_{6}$-DMSO): $177.95,176.34,172.55,169.80$, $150.91,140.44,132.41,132.02,131.76,110.00,109.58,80.59,77.14,54.09,52.81$, 38.81, 36.68, 27.68, 26.62, 25.31, 24.82. FT-IR (KBr): 3309 (br), 2939, 2861, 1776, $1701,1586,1518,1450,1400,1369,1345,1296,1243,1181,1153,1036,970,802,632$, and $550 \mathrm{~cm}^{-1}$.

Table 1: GPC traces of the polymers and copolymers (determined by GPC in THF relative to polystyrene standards. [a] Yields of polymers obtained after precipitation into hexanes.

\begin{tabular}{|c|c|c|c|c|}
\hline Polymer & Mn (calculated) & $\mathrm{Mn} / 10^{3}(\exp )$. & Yield (\%) $^{[\mathrm{a}]}$ & PDI \\
\hline $\mathbf{6}$ & 4211 & 4.1 & 90 & 1.11 \\
\hline $\mathbf{7}$ & 1741 & 2.9 & 88 & 1.08 \\
\hline $\mathbf{8}$ & 12791 & 17.1 & 82 & 1.09 \\
\hline $\mathbf{9}$ & 16911 & 21.1 & 79 & 1.09 \\
\hline $\mathbf{1 0}$ & 11141 & 15.2 & 78 & 1.12 \\
\hline $\mathbf{1 1}$ & 12791 & 17.6 & 85 & 1.12 \\
\hline $\mathbf{1 2}$ & 16911 & 22.7 & 91 & 1.14 \\
\hline
\end{tabular}


